\title{
Self efficacy in sleep disorder patients
}

\section{Saba Khan and Nalini Totuka}

Received: 18.04.18; Revised: 17.10.2018; Accepted: 29.10.2018

See end of the paper for authors' affiliations

\section{Saba Khan}

Department of Human Development, The IIS University, Jaipur (Rajasthan) India
ABSTRACT : Sleep, a complex biologic process controlled by the nervous system and is important for proper cognitive, immune and metabolic function. As the aging occurs, it leads to changes in sleep, and the prevalence of sleep disorders increases with age, having a negative impact on the quality of life and well being in older adults. The present study was aimed to examine the effect of sleep disorder on self efficacy of adults. The sample consisted of 240 patients, 120 sleep disorder and 120 non-sleep disorder patients. Test of sleep disorder screening questionnaire by Emory Health Care Centre and Academic Medical College Atlanta, Georgia and self efficacy by Pareek (1988) were used. For analysis of data Mean, SD and t test were used. Results revealed that patients with sleep disorder have poor self efficacy in comparison to normal adults. Patients with Insomnia sleep disorder have better self efficacy in comparison to other types of sleep disorder patients.

KEY WORDS: Sleep disorder, Self efficacy,Quality of life, Well being

- HOW TO CITE THIS PAPER : Khan, Saba and Totuka, Nalini (2018). Self efficacy in sleep disorder patients. Asian J. Home Sci., 13 (2) : 528-531, DOI: 10.15740/HAS/AJHS/13.2/528-531. Copyright@ 2018: Hind Agri-Horticultural Society. 